\title{
KARAKTERISTIK MIKROSKOPIK KERAMIK BATAKO TERHADAP VARIASI PENAMBAHAN SEKAM TEBU
}

\author{
Jan Ady ${ }^{1)}$ dan Aziza Anggi Maiyanti ${ }^{1)}$ \\ ${ }^{1)}$ Departemen Fisika,Fakultas Sains dan Teknologi \\ Universitas Airlangga Surabaya \\ Kampus C Mulyorejo, Surabaya 60115 \\ e-mail : djavin_velin@yahoo.com
}

\begin{abstract}
ABSTRAK
Telah dilakukan penelitian tentang pengaruh penambahan sekam tebu pada sifat mikroskopis batako sehingga dapat diketahui komposisi sekam tebu paling baik untuk bahan pengikat dari batako tersebut. Sampel yang digunakan batako dengan penambahan sekam tebu diayak dan tanpa diayak dengan persentase masing - masing $0 \mathrm{wt} \%, 3 \mathrm{wt} \%$, 6wt $\%$, 9wt $\%, 12 \mathrm{wt} \%, 15 \mathrm{wt} \%$. Variasi optimum terlihat pada variasi $12 \mathrm{wt} \%$ untuk penambahan sekam tebu tanpa diayak dan $15 \mathrm{wt} \%$ untuk penambahan sekam tebu diayak. Nilai porositas batako rata-rata normal yaitu sebesar $(8,119 \pm 3,866) \%$ dan nilai densitas rata-rata $(2,343 \pm 0,211) \mathrm{gr} / \mathrm{cm}^{3}$, setelah penambahan sekam tebu maka terjadi perbaikan sifat porositas dan densitas yaitu $(7,692 \pm 2,492) \%$ dan $(2,387 \pm$ $0,087) \mathrm{gr} / \mathrm{cm}^{3}$ untuk variasi penambahan sekam tebu tanpa pengayakan, sedangkan nilai porositas dan densitas untuk penambahan variasi sekam tebu dengan pengayakan adalah $(3,846 \pm 0,427) \%$ dan $(2,674 \pm 0,125) \mathrm{gr} / \mathrm{cm}^{3}$. Setelah melalui uji XRD terlihat pembentukan fasa baru yaitu $\mathrm{Al}_{0,03} \mathrm{Fe}_{0,15} \mathrm{Mg}_{1,82} \mathrm{O}_{6} \mathrm{Si}_{1,97}$ (Enstatite) yang diidentifikasikan memiliki pengaruh perbaikan sifat densitas batako. Berdasarkan nilai porositas dan nilai densitas diatas maka batako dengan variasi penambahan sekam tebu telah berhasil memperbaiki sifat mikroskopis batako meskipun pada penambahan sekam tebu tanpa pengayakan memiliki nilai porositas dan densitas tidak stabil.
\end{abstract}

Kata Kunci : Keramik Batako, Sekam Tebu, Porositas, Densitas, XRD

\section{PENDAHULUAN}

Definisi keramik mencakup semua bahan bukan logam dan anorganik yang berbentuk padat. Umumnya senyawa keramik lebih stabil dalam lingkungan termal dan kimia dibandingkan elemennya. Bahan baku keramik yang umum dipakai adalah felspard, ball clay, kwarsa, kaolin, dan air. Sifat keramik sangat ditentukan oleh struktur kristal, komposisi kimia dan mineral bawaannya.Klasifikasi keramik meliputi keramik modern dan keramik tradisional. Dalam penelitian ini bahan keramik yang digunakan masuk dalam kategori keramik modern yaitu batako. Batako merupakan keramik modern yang biasa digunakan untuk bahan dasar bangunan sebagai pengganti batu bata. Hasil penelitian laboratorium yang pernah dilakukan untuk batako berumur 28 hari diperoleh : berat fisik rata-rata sebesar $12,138 \mathrm{~kg}$, densitas rata-rata sebesar 2,118 $\mathrm{gr} / \mathrm{c}$, penyerapan air sebesar $12,876 \%$ dan kuat tekan rata-rata sebesar $1,97 \mathrm{MPa}$ (Darmono, 2009).
Seiring dengan perkembangan jaman dan kemajuan teknologi, sekam tebu yang dahulunya hanya digunakan sebagai abu gosok, sudah mulai dimanfaatkan dalam industri bahan bangunan, seperti pada penelitian yang dilakukan oleh Hidayati pada tahun 2010 dengan judul Pengaruh Penambahan Abu Ampas Tebu Terhadap Sifat Fisis dan Mekanis Batako. Pada penelitian ini digunakan variasi penambahan sekam tebu dengan persentase $10 \mathrm{wt} \%$, 20wt \%, 30wt \%, 40wt\%, 50wt\%. Peneliti menggunakan perbandingan semen, pasir, air sebesar 1:4:0,5. Penelitian ini menambahkan sekam tebu pada proses pembuatan sehingga diharapkan memperbaiki sifat fisis dan mekanis batako meliputi penyerapan air, densitas, kuat pukul, kuat tekan dan kekerasan. Selain itu terdapat juga penelitian yang dilakukan oleh Emelda Sihotang pada tahun 2010 dengan judul Pemanfaatan Abu Ampas Tebu pada Pembuatan Mortar. Penelitian ini menggunakan variasi penmabahan sekam tebu 3\%, 6\%, 9\%, $12 \%$ dan $15 \%$. Penelitian Sihotang mendapatkan 
hasil porositas semakin baik tetapi tidak menghitung nilai densitas sedangkan pada penelitian Hayati diketahui nilai densitas. Kedua penelitian diatas tidak meneliti tentang pengaruh penambahan sekam tebu dengan sifat mikroskopik sebuah bahan.

Ulasan di atas memberikan inspirasi untuk mengkarakterisasi material keramik batako baik yang sudah ditambahkan dengan variasi sekam tebu ataupun yang belum ditambahkan sekam tebu terkait dengan sifat mikroskopik yang dikandung oleh material keramik batako sehingga dapat menjadikan material keramik batako yang telah disintesis dengan sekam tebu mempunyai kelebihan dibandingkan dengan material keramik batako tanpa variasi apapun.

\section{METODE PENELITIAN}

\section{Pembuatan Sampel}

Pencampuran material dilakukan dengan menggunakan mixer sesuai dengan proporsi dalam rancangan percobaan di atas. Pertama, agregat halus dicampur dengan sekam tebu sampai merata pencampurannya. Kedua, semen Portland tipe-1 ditaburkan pada permukaan pencampuran tersebut. Setelah ketiganya merata, dilubangi bagian tengahnya seperti sebuah kawah untuk ditaburi air PDAM lalu diaduk hingga campuran tersebut saling mengikat dan homogen menjadi sebuah adonan pasta.

Pencetakan material dilakukan setelah pencampuran dan pengadukan material. Adonan batako basah dimasukkan di dalam cetakan balok $(10 \times 5 \times 5) \mathrm{cm}$. Sebelum dimasukkan ke dalam cetakan, terlebih dahulu cetakan diolesi dengan vaselin. Setelah dimasukkan ke cetakan, adonan pasta dipress hingga padat dan ditutup dengan kain basah selama 24 jam.

Pengeringan material dilakukan setelah batako dicetak dan dibiarkan selama 24 jam lalu dikeluarkan dari cetakannya. Selanjutnya diletakkan di rendam di bak perendaman selama 27 hari. Pada hari ke 28 dilakukan proses pengeringan atau pengangkatan material selama 24 jam dilanjutkan dengan pengujian mikroskopik, porositas dan densitas pada mortar tersebut.

\section{Pengujian Porositas}

Setelah melalui proses perendaman dan pengeringan maka dilakukan uji porositas menggunakan persamaan :

Porositas $(\%)=\frac{m_{b}-m_{k}}{v_{b}} \times \frac{1}{\rho_{\text {air }}} \times 100 \%$

Dimana :

$\mathrm{m}_{\mathrm{b}}=$ Massa basah dari benda uji (gram)

$\mathrm{m}_{\mathrm{k}}=$ massa kering dari benda uji (gram)

$\mathrm{v}_{\mathrm{b}}=$ Volume benda uji

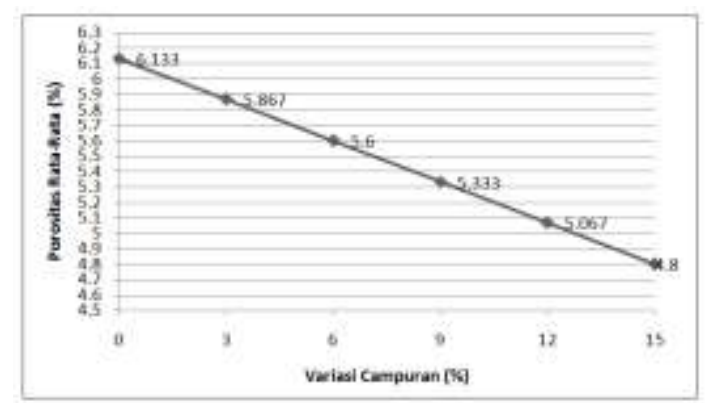

Gambar 1. Grafik Hasil Uji Porositas Batako dengan variasi Sekam Tebu

\section{Pengujian Densitas}

Untuk pengukuran densitas batako mengacu pada standard ASTM C 134-95 dan dihitungdengan persamaan (Juwairiah,2009):

$$
\rho_{\mathrm{pc}}=\frac{\mathrm{m}_{\mathrm{s}}}{\mathrm{m}_{\mathrm{b}}-\left(\mathrm{m}_{\mathrm{s}}-\mathrm{m}_{\mathrm{k}}\right)} \times \rho_{\text {air }}
$$

Dimana :

$\rho p c=$ densitas $\left(\mathrm{gr} / \mathrm{cm}^{3}\right)$

$\mathrm{ms}=$ massa sample kering $(\mathrm{gr})$

$\mathrm{mb}=$ massa sample setelah di rendam $(\mathrm{gr})$

$\mathrm{mg}=$ massa sample digantung didalam air (gr)

$\mathrm{mk}=$ massa kawat penggantung $(\mathrm{gr})$

pair $=$ densitas air $=1(\mathrm{gr} / \mathrm{cm} 3)$

Hasil penelitian laboratorium yang pernah dilakukan untuk batako berumur 28 hari diperoleh: berat fisik rata-rata sebesar $12,138 \mathrm{~kg}$, densitas rata-rata sebesar 2,118 $\mathrm{gr} / \mathrm{cm} 3$, penyerapan air sebesar $12,876 \%$, dan kuat tekan rata-rata sebesar $1,97 \mathrm{MPa}$ (Darmono, 2009).

\section{Uji XRD}

Pengujian XRD dilakukan setelah melewati uji porositas dan uji densitas. Uji XRD dilakukan untuk mengetahui pengaruh sifat mikroskopik batako dengan variasi penambahan sekam tebu dengan perbaikan nilai porositas dan nilai densitas. 


\section{HASIL DAN PEMBAHASAN}

Sekam tebu yang digunakan untuk variasi penambahan pada batako harus merupakan silika amorf dikarenakan bentuk silika amorf akan memberi pengaruh peningkatan kekuatan keramik yang lebih besar dibanding dengan bentuk fase kristalnya.Berdasarkanpenelitian Hanafi dan Nandang (2010), memaparkan bahwa kuat patah maksimum diberikan oleh bentuk amorf sebesar 940 dyne $/ \mathrm{cm}^{2}$ yang lebih tinggi dari kuat patah keramik Indonesia dalam literatur. Silika amorf diperoleh dengan cara membakar sekam tebu dengan suhu antara $500^{\circ} \mathrm{C}-600^{\circ} \mathrm{C}$ dan setelah melalui uji XRD maka akan terlihat hasil seperti pada Gambar 2.

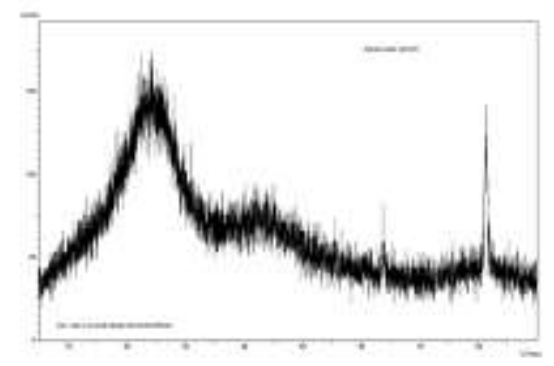

Gambar 2. Hasil Uji XRD Sekam Tebu

Hasil XRD batako dengan variasi penambahan sekam tebu disajikan pada Gambar 3, 4 dan 5.

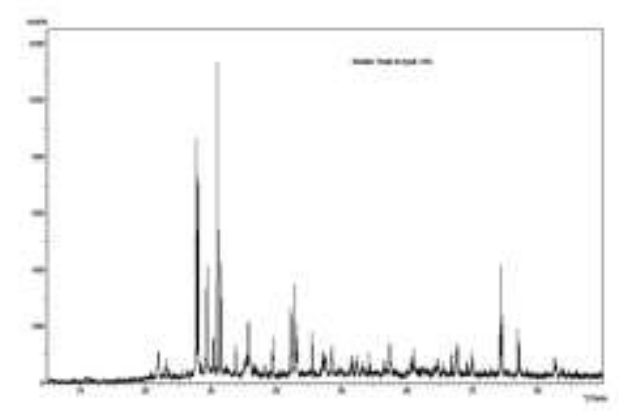

Gambar 3. Hasil Uji XRD Variasi 0 wt\%

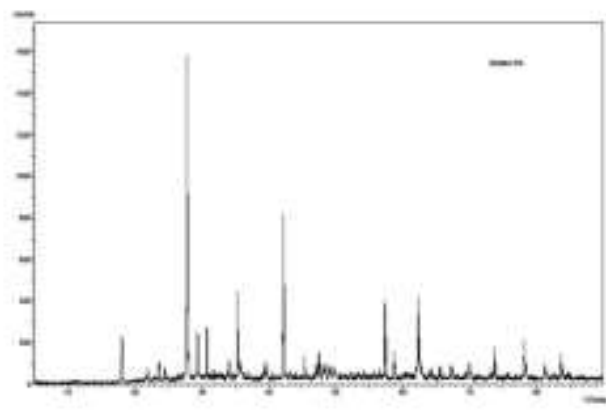

Gambar 4. Hasil Uji XRD Variasi 12wt\% dengan pengayakan

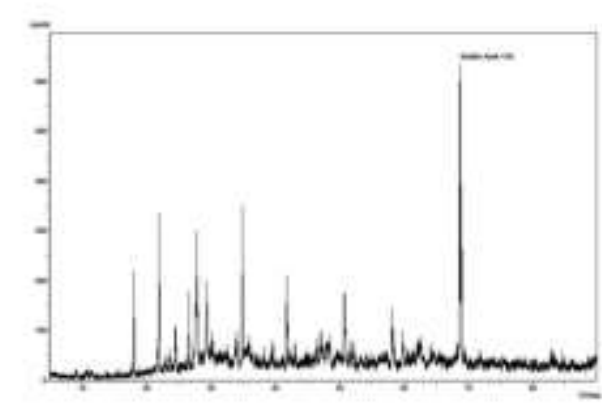

Gambar 5. Hasil Uji XRD Variasi 15wt\% tanpa pengayakan

Berdasarkan analisis XRD pada Gambar 3 menunjukkan bahwa batako sebelum penambahan sekam tebu didominasi oleh dua fasa yaitu $\mathrm{SiO}_{2}$ sebanyak 62,5\% dan $\mathrm{Al}_{2} \mathrm{ClF}_{25} \mathrm{Sr}_{10}$ (Strontium Hexafluoroaluminate fluoride chloride) sebanyak $37,5 \%$. Hasil XRD pada Gambar 4mengandung 3 fasa dominan yakni $\mathrm{SiO}_{2}$ sebanyak1,8\%, $\mathrm{Al}_{2} \mathrm{ClF}_{25} \mathrm{Sr}_{10}$ sebanyak3,0\% dan $\mathrm{Al}_{0,03} \mathrm{Fe}_{0,15} \mathrm{Mg}_{1,82} \mathrm{O}_{6} \mathrm{Si}_{1,97}$ (Enstatite) sebanyak 95,2\%. Hasil Grafik XRD pada Gambar 4 mengandung 3 fasa dominan yaitu $\mathrm{SiO}_{2}$ sebanyak $17,3 \%, \mathrm{Al}_{2} \mathrm{ClF}_{25} \mathrm{Sr}_{10}$ sebanyak $10,6 \%$ dan $\quad \mathrm{Al}_{0,03} \mathrm{Fe}_{0,15} \mathrm{Mg}_{1,82} \mathrm{O}_{6} \mathrm{Si}_{1,97}$ (Enstatite) sebanyak 72,1\%. Fasa enstatite terlihat mulai muncul pada variasi penambahan sekam tebu $12 \mathrm{wt} \%$.

Perbedaan dari ke tiga sampel yang di uji adalah persentase kedua fasa dominan tersebut dan terlihat juga terdapat fasa baru yang terbentuk pada hasil pengujian XRD batako yang telah divariasikan dengan sekam tebu yaitu fasa $\mathrm{Al}_{0,03} \mathrm{Fe}_{0,15} \mathrm{Mg}_{1,82} \mathrm{O}_{6} \mathrm{Si}_{1,97}$ (Enstatite). Pembentukan fasa enstatite disajikan dalam lampiran 3 point $\mathrm{B}$ dan $\mathrm{C}$. 
Munculnya senyawa enstatite di duga berperan dalam perbaikan sifat densitas batako.

Berdasarkan(Dana,E.S,1892) dijelaskan juga bahwa Enstatite tersusun atas senyawa pada Tabel 1.
Tabel 1. Senyawa penyusun Enstatite

\begin{tabular}{|c|c|}
\hline No & Senyawa \\
\hline 1 & $\mathrm{SiO}_{2}$ \\
\hline 2 & $\mathrm{TiO}_{2}$ \\
\hline 3 & $\mathrm{Al}_{2} \mathrm{O}_{3}$ \\
\hline 4 & $\mathrm{Fe}_{2} \mathrm{O}_{3}$ \\
\hline 5 & $\mathrm{Cr}_{2} \mathrm{O}_{3}$ \\
\hline 6 & $\mathrm{FeO}$ \\
\hline
\end{tabular}

Tabel 2. Hasil Uji Porositas Batako

\begin{tabular}{|c|c|c|c|}
\hline \multirow{2}{*}{ No } & Variasi & \multicolumn{2}{|c|}{ Porositas Rata - Rata (\%) } \\
\cline { 3 - 4 } & $(\%)$ & Tidak diayak & Diayak \\
\hline 1 & $3 \mathrm{wt}$ & $9,402 \pm 3,140$ & $7,692 \pm 0,855$ \\
\hline 2 & $6 \mathrm{wt}$ & $12,820 \pm 0,457$ & $6,838 \pm 1,298$ \\
\hline 3 & $9 \mathrm{wt}$ & $11,111 \pm 2,898$ & $5,128 \pm 1,047$ \\
\hline 4 & $12 \mathrm{wt}$ & $7,692 \pm 2,492$ & $4,273 \pm 4,472 \times 10^{-4}$ \\
\hline 5 & $15 \mathrm{wt}$ & $12,820 \pm 1,788$ & $3,846 \pm 0,427$ \\
\hline
\end{tabular}

Berdasarkan Tabel 1 terlihat penyusun dari enstatite hampir sama dengan penyusun sekam tebu, pasir dan semen yang terdiri dari $\mathrm{SiO}_{2}, \mathrm{Al}_{2} \mathrm{O}_{3}$ dan $\mathrm{Fe}_{2} \mathrm{O}_{3}$ sedangkan setelah mengalami pencampuran maka terjadi perubahan pada senyawa $\mathrm{TiO}_{3}$ menjadi $\mathrm{TiO}_{2}$ hal ini diduga terjadi karena pada saat pencampuran bahan terjadi suatu reaksi penggantian atom sehingga terbentuk juga senyawa-senyawa yang lain. Dikarenakan pasir, sekam tebu dan semen mempunyai senyawa pembentuk yang identik maka jika ketiga bahan tersebut dicampurkan maka terdapat kemungkinan terbentuk fasa enstatite.

Karakterisasi perbaikan sifat porositas ditunjukkan pada Tabel 2 dan Gambar 6. Sebagai pembanding terdapat variasi $0 \mathrm{wt} \%$ dengan nilai porositas adalah $8,119 \pm 3,866 \%$ dan nilai densitas sebesar $2,343 \pm 0,211 \mathrm{gr} / \mathrm{cm}^{3}$.

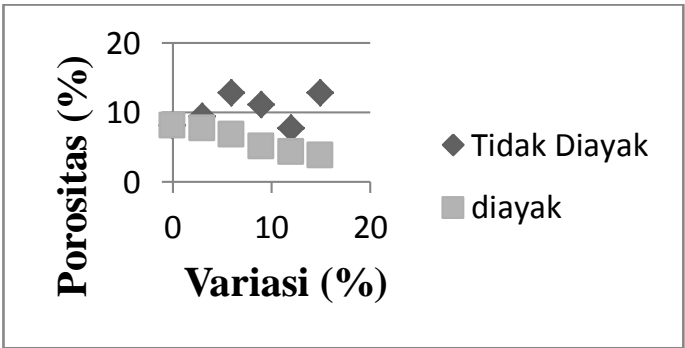

Gambar 6. Grafik Hasil Uji Porositas Batako

Porositas yang stabil dihasilkan pada penambahan variasi sekam tebu yang telah melalui pengayakan yaitu mengalami perbaikan disetiap persentase sekam tebu yang ditambahkan sehingga didapatkan hasil yang optimum pada variasi penambahan sekam tebu sebanyak $15 \%$. Sekam tebu dapat berperan sebagai pengisi antara partikel partikel pembentuk batako sehingga kedapan batako akan menjadi bertambah sehingga permeabilitas semakin kecil.

Partikel-partikel $\mathrm{SiO} 2$ pada sekam tebu yang sangat halus memiliki luas permukaan interaksi yang tinggi. Partikelpartikel tersebut berinteraksi dengan campuran pasir dan semen yang merupakan bahan baku utama dari batako. Semakin banyak partikel yang berinteraksi, semakin kuat pula batako. Semakin kuat batako maka semakin berkurang juga nilai porositas batako sehingga didapatkan nilai porositas batako yang optimum.(Mulyati, 2010).

Menurut penelitian Mulyati pada tahun 2010 dengan penambahan sekam tebu melalui pengayakan 200 mess atau setara 
dengan 75 mikron maka sekam tebu memiliki ukuran lebih kecil dibandingkan ukuran partikel semen yaitu 120 mess atau setara dengan 125 mikron sehingga sekam tebu dapat memasuki pori-pori yang ditinggalkan oleh air tetapi tidak dapat dimasuki oleh ukuran partikel semen. Sehingga saat sekam tebu dapat mengisi pori-pori yang ditinggalkan oleh air maka rongga-rongga pori dalam batako akan semakin sedikit perbandingannya dengan volum batako tersebut sehingga nilai porositasnya mengalami perbaikan di setiap penambahan persentase sekam tebu yang melalui proses pengayakan.

Hasil Karakterisasi perbaikan nilai densitas ditunjukkan pada Tabel 3 dan Gambar 7.

Tabel 3. Hasil Uji Densitas Batako

\begin{tabular}{|c|c|c|c|}
\hline \multirow{2}{*}{ No } & Varia & Densitas Rata - Rata $\left(\mathrm{gr} / \mathrm{cm}^{3}\right)$ \\
\cline { 3 - 4 } & si $(\%)$ & Tidak diayak & Diayak \\
\hline 1 & $3 \mathrm{wt}$ & $1,745 \pm 0,145$ & $2,399 \pm 0,049$ \\
\hline 2 & $6 \mathrm{wt}$ & $1,897 \pm 0,079$ & $2,452 \pm 0,044$ \\
\hline 3 & $9 \mathrm{wt}$ & $2,060 \pm 0,145$ & $2,516 \pm 0,123$ \\
\hline 4 & $12 \mathrm{wt}$ & $2,387 \pm 0,087$ & $2,631 \pm 0.079$ \\
\hline 5 & $15 \mathrm{wt}$ & $1,879 \pm 0,129$ & $2,674 \pm 0,125$ \\
\hline
\end{tabular}

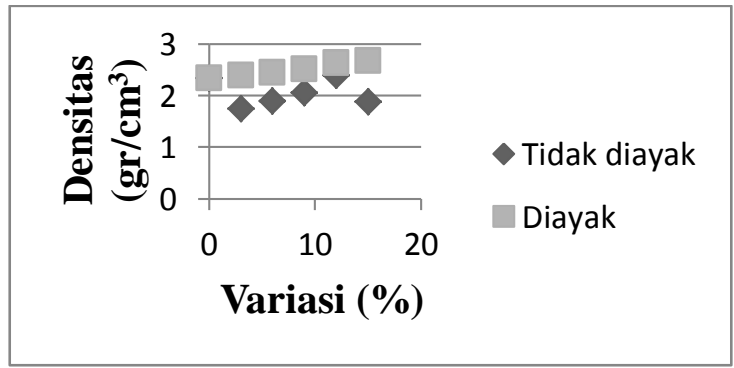

Gambar 7. Hasil uji Densitas Batako

Jika diperhatikan pada hasil Grafik uji XRD yakni Gambar 4 dan 5terlihat terdapat fasa baru yang diindikasikan menjadi salah satu penyebab perbaikan sifat yakni fasa $\mathrm{Al}_{0,03} \mathrm{Fe}_{0,15} \mathrm{Mg}_{1,82} \mathrm{O}_{6} \mathrm{Si}_{1,97}$ (Enstatite).

Gambar 3 menunjukkan terdapat dua fasa dominan yakni $\mathrm{SiO}_{2}$ dan $\mathrm{Al}_{2} \mathrm{ClF}_{25} \mathrm{Sr}_{10}$ (Strontium Hexafluoroaluminate fluoride chloride) dengan nilai persentase yang berbeda. Berdasarkan penelitian (Brownel, L.E dan Young, E.H, 1993) didapatkan nilai densitas dari $\mathrm{SiO}_{2}$ (Quartz) adalah 2,648 $\mathrm{gr} / \mathrm{cm}^{3}$ sedangkan menurut penelitian (N.N. Greenwood,1997) terlihat bahwa nilai densitas $\quad \mathrm{Al}_{2} \mathrm{ClF}_{25} \mathrm{Sr}_{10} \quad$ (Strontium Hexafluoroaluminate fluoride chloride) yakni $3,69 \mathrm{gr} / \mathrm{cm}^{3}$.

Gambar 4 dan 5 masih terdapat dua fasa yang sama tetapi terlihat terbentuk fasa baruyaitu $\mathrm{Al}_{0,03} \mathrm{Fe}_{0,15} \mathrm{Mg}_{1,82} \mathrm{O}_{6} \mathrm{Si}_{1,97}$ (Enstatite) dengan persentase yang sangat tinggi. Berdasarkan Morimoto, $\mathrm{N}$ dan Koto,K,1969diketahui Enstatitememiliki nilai densitas 3,9 gr/ $\mathrm{cm}^{3}$.

Berdasarkan data densitas masingmasing fasa yang telah didapatkan dan persentase masing-masing fasa yang telah di ketahui maka terlihat bahwa fasa $\mathrm{Al}_{0,03} \mathrm{Fe}_{0,15} \mathrm{Mg}_{1,82} \mathrm{O}_{6} \mathrm{Si}_{1,97}$ (Enstatite) memiliki nilai densitas paling tinggi sehingga dengan nilai densitas tersebut serta persentase yang ditunjukkan pada Gambar 4 dan Gambar 5 yang tinggi pula dapat disimpulkan bahwa Enstatite mempunyai pengaruh pada perbaikan nilai densitas batako.

\section{KESIMPULAN}

1. Metode Penambahan Silika Amorf Sekam Tebu dapat digunakan untuk mensintesis material keramik batako dengan nilai porositas dan densitas yang lebih baik dibandingkan dengan batako murni. Porositas batako murni memiliki nilai rata-rata $(8,119 \pm 3,866) \%$ dan Densitas batako murni memiliki nilai $(2,343 \pm$ $0,211) \mathrm{gr} / \mathrm{cm}^{3}$. Sedangkan nilai porositas setelah penambahan sekam tebu adalah $(7,692 \pm 2,492) \%$ untuk yang tidak diayak dan $\left(3,846 \pm 4,472 \times 10^{4}\right) \%$ untuk batako dengan variasi penambahan sekam tebu diayak, sedangkan densitas batako yang dihasilkan setelah mendapatkan penambahan silika amorf sekam tebu adalah $(2,387 \pm 0,087) \mathrm{gr} / \mathrm{cm}^{3}$ untuk penambahann variasi sekam tebu tanpa pengayakan dan penambahan sekam tebu yang mengalami pengayakan didapatkan nilai $(2,674 \pm 0,125) \mathrm{gr} / \mathrm{cm}^{3}$.

2. Hasil dari uji XRD menggambarkan penambahan silika amorf sekam tebu dapat memperbaiki sifat mikroskopis batako dengan adanya pembentukan fasa baru yaitu $\mathrm{Al}_{0,03} \mathrm{Fe}_{0,15} \mathrm{Mg}_{1,82} \mathrm{O}_{6} \mathrm{Si}_{1,97}$ (Enstatite) yang berperan dalam memperbaiki nilai densitas batako dikarenakan Enstatite memiliki nilai densitas yang cukup tinggi dibandingkan dengan fasa $\mathrm{SiO}_{2}$ (Quartz) dan 
$\mathrm{Al}_{2} \mathrm{ClF}_{25} \mathrm{Sr}_{10}$ (Strontium Hexafluoroaluminate fluoride chloride).

\section{DAFTAR PUSTAKA}

Brownell,L.E. Young, E.H. 1993. Precipitation chemystry. New York.

Dana, E.S. 1892. Dana's System of Mineralogy 6th edition. 346-348.

Darmono. 2009. Penerapan Teknologi Produksi Bahan Bangunan Berbahan Pasir Bagi Korban Gempa Di Kulonprogo Serta Analisis Mutu dan Ekonominya.Yogyakarta:Universitas Negeri Yogyakarta.

Hayati, E.K. 2007. Buku Ajar Dasar-Dasar Analisa Spektroskopi. UIN Press, Malang.

Herdianita. 2000. Pengukuran Kristalinitas Silika Berdasarkan Metode Difraktometer Sinar-X. Bandung: Institut Teknologi Bandung

Hidayati,Nurwahyu. 2010. Pengaruh Penambahan Abu Ampas Tebu Terhadap Sifat Fisis dan Mekanis Batako. Departemen Fisika Fakultas Matematika dan Ilmu Pengetahuan Alam. Medan: Universitas Sumatera Utara.

Jaturapitakkul,Chai. 2009. Utilization of Bagase Ash a Pozzolanic Material in Concrete. Thailand:University of Technology Thonbury.

Joelianingsih. 2004. Peningkatan Kualitas Genteng Keramik Dengan Penambahan Sekam Padi Dan Daun Bambu (Makalah Pribadi Falsafah Sains (PPS 702) Sekolah Pasca Sarjana / S3). Bogor: Institut Pertanian Bogor.

Juwairiah. 2009. Efek Komposisi Agregat Batu Apung dan Epoxy Resin Dalam Pembuatan Polymer Concrete Terahadap Karakteristiknya. Medan:Universitas Sumatera Utara.

Morimoto,N. Koto,K. 1969. The Crystal Structure of Orthoenstatite.Zeitschrift fur kristallographie.

Mulyati, Sri. 2010. Pengaruh Persen Massa Hasil Pembakaran Serbuk Kayu dan Ampas Tebu Pada Mortar Terhadap Sifat Mekanik dan Sifat Fisisnya. Universitas Andalas.
Greenwood, N.N. 1997. Chemistry of the element. Butterwort-Heinemann. United Kingdom:Oxford..

Ratnasari,D. 2009. Tugas Kimia Fisik X-Ray Diffraction $\quad(X R D) . \quad$ Surakarta: Universitas Sebelas Maret Surakarta.

S.A.Hanafi dan R.A. Nandang. 2008. Studi Pengaruh Bentuk Silika dari Sekam tebu terhadap Kekuatan Produk Keramik. Serpong: Pusat Penelitian Kimia LIPI

Sihotang,Emelda. 2010. Pemanfaatan Sekam tebu pada Pembuatan Mortar. Medan:Universitas Sumatera Utara

Sitorus, T.K. 2009. Pengaruh Penambahan Silika Amorf Dari Sekam Padi Terhadap Sifat Mekanis Dan Sifat Fisis Mortar. Medan: Universitas Sumatra Utara.

Simbolon, T. 2009. Pembuatan dan Karaterisasi Batako Ringan Yang Terbuat dari Styoform Semen.Medan:Uuniversitas Sumatera Utara

Sukmawati, Rahman. 2010. Kajian Eksperimental Pengaruh Aspek Lekatan Agregat Kasar Terhadap Mortar pada Kuat Tekan Beton. Semarang:Universitas Diponegoro

Umah,Saiyidatul. 2010. Penambahan Abu Sekam Padi dari Berbagai Suhu Pengabuan Terhadap Plastisitas Kaolin. Malang: Universitas Islam Negeri Maulana Malik Ibrahim

Wiboweo, FX. Nurwadji, John Tri Hatmoko, Haryanto Yoso Wigroho. 2006. Pengembangan Alat Pengolah Limbah Sekam tebu Menjadi Pozolan. Yogyakarta:Universitas Atma Jaya.

Wijanarko W. 2008. Analisis Bahan Jerami Padi Dalam Bentuk Block atau Kotak Sebagai Bahan Pengisi Batako. Surakarta:Universitas Sebelas Maret. 